\title{
Determination of metal impurities in titanium dioxide using slurry sample introduction by axial viewing inductively coupled plasma optical emission spectrometry
}

\author{
Zheng Wang, ${ }^{a, b}$ Zheming Ni, ${ }^{c}$ Deren Qiu, ${ }^{b}$ Tianyu Chen, ${ }^{a}$ Guangyi Tao ${ }^{a}$ and \\ Pengyuan Yang* $* b$ \\ ${ }^{a}$ Shanghai Institute of Ceramics, Chinese Academy of Sciences, Shanghai 200050, China \\ ${ }^{b}$ Department of Chemistry, Fudan University, Shanghai 200433, China. \\ E-mail: pyyang@fudan.edu.cn \\ ${ }^{c}$ Research Center for Eco-Environmental Sciences, Academia Sinica, P.O. Box 2871, \\ Beijing 100085, China
}

Received 1st July 2003, Accepted 14th November 2003

First published as an Advance Article on the web 15th December 2003

\begin{abstract}
A slurry sample introduction technique for the analysis of $\mathrm{TiO}_{2}$ powders by axial viewing ICP-OES is reported. Relationships between stable slurries and the conditions, such as particle size, $\mathrm{pH}$, dispersant and its amount, were experimentally investigated. Slurries were prepared by mixing the $\mathrm{TiO}_{2}$ powder with the dispersant poly(acrylate amine) $\left(\mathrm{NH}_{4} \mathrm{PAA}\right)$ and agitation in an ultrasonic bath to ensure good dispersion. The $\mathrm{pH}$ of the medium and amount of dispersant has been optimized. Impurities in $\mathrm{TiO}_{2}$ were determined by an axial viewing ICP-OES spectrometer. As representatives, a Standard Reference Material $154 \mathrm{~b}$ of $\mu \mathrm{m}$ particle size $\mathrm{TiO}_{2}$ and a nm particle size $\mathrm{TiO}_{2}$ were selected and determined for micro and trace impurities. Analytical results obtained via slurry sample introduction were compared with those via nebulization of aqueous solutions prepared by acid digestion and fusion digestion. The determined results by slurry introduction were in good accordance with the stated values, which verified that the calibration curves could be established by aqueous standards.
\end{abstract}

\section{Introduction}

Titanium dioxide is used in various fields of technology such as oxygen sensors, capacitors or diezoelectric applications. Its properties are significantly affected by some metal impurities. ${ }^{1-3}$ Semiconductor photo-catalysts have attracted much attention because of their applicability in the treatment of wastes and pollutants in air and water. ${ }^{4}$ Titanium dioxide is also interesting in application to chemical conversion of solar energy, for example, decomposition of water. For these purposes, $\mathrm{TiO}_{2}$ particles with small sizes have been commonly used, especially $\mathrm{nm}$ particle size titanium dioxide. The large specific surface area is extraordinarily effective for capturing low concentration chemicals. The presence of oxides of metals influence the characteristics of $\mathrm{TiO}_{2}{ }^{5}$

Therefore, determination of impurities in $\mathrm{TiO}_{2}$ powders demands a powerful routine analytical method. The traditional chemical analysis of $\mathrm{TiO}_{2}$ generally involves tedious procedures for sample preparation. Even using modern strategies, such as microwave-assisted acid digestion, $\mathrm{TiO}_{2}$ samples may still not be easy to bring into solution completely, and the choice of acid mixture and amount and the heating program is critical. ${ }^{6}$ An alternative is the slurry sample preparation. Inductively coupled plasma optical emission spectrometry (ICP-OES) is a perfect technique for the determination of impurities in $\mathrm{TiO}_{2}$. Nebulization of a solution is normally used for sample introduction but slurries can be introduced as well with modification of the nebulizer and nebulization chamber. ${ }^{7,8}$ In addition to the well-known multi-element capacity, recent equipment with a quartz torch in axial position makes it possible to obtain better sensitivity. Axial viewing of the ICP has the potential of about 10 -fold improvement of LODs. ${ }^{9,10}$ This makes it more useful in micro and trace element determination.

In a comprehensive review of axial viewing ICP-OES, ${ }^{11}$ analyses of slurries were scarcely evaluated. Marjanovic et al. ${ }^{12}$ and Silva et $a l .{ }^{8}$ used axial viewing ICP-OES for the analysis of slurries of cement samples and verified that it was effective and without any undesirable particle deposition in the pre-optics interface and free from severe spectral interferences. Broekaert et $a l .{ }^{13}$ introduced $\mathrm{TiO}_{2}$ solid samples to the plasma using sodium hexametaphosphate as dispersant and observed the samples with a vertical viewing inductively coupled plasma optical emission spectrometer. In the case of suspension introduction, detection limits are slightly higher than those for aqueous solutions with the same titanium concentrations, with only few exceptions. Peng et al. ${ }^{3,14}$ directly determined $\mathrm{Cr}$, $\mathrm{Cu}, \mathrm{Fe}$ and $\mathrm{V}$ in titanium dioxide powder by fluorination assisted electrothermal vaporization ICP-OES. Farinas et al. ${ }^{15}$ published an excellent study on the colloidal stability of ceramic suspensions for the nebulization of slurries for ICPOES. Txiton-X-100 or a glycerol-Kodak photoflow mixture was found not to stabilize and disperse alumina slurries. Wang et al. ${ }^{16}$ used poly(acrylate amine) $\left(\mathrm{NH}_{4} \mathrm{PAA}\right)$ as a dispersant to stabilize zirconia suspensions and found it was an excellent dispersant.

The present work reports the use of an axially viewed ICP for analysis of $\mathrm{TiO}_{2}$ slurries prepared by direct suspension of the powder. Poly(acrylate amine) $\left(\mathrm{NH}_{4} \mathrm{PAA}\right)$ was used as dispersant and $\mathrm{Fe}, \mathrm{P}, \mathrm{Pb}, \mathrm{Si}$ and $\mathrm{Mg}$ in $\mathrm{nm}$ and $\mu \mathrm{m}$ particle size $\mathrm{TiO}_{2}$ were determined. The results are presented and discussed.

\section{Experimental}

\section{Instrumentation}

All determinations were performed on a VISTA AX simultaneous ICP-OES spectrometer with axial view configuration (Varian, Australia). The characteristics of the spectrometer have been described by Zander et al. ${ }^{17}$ It has a charge-coupled detector (CCD) that makes it possible to detect a twodimensional spectrum. The sample introduction system 
Table 1 Instrumentation and operating conditions

\begin{tabular}{ll}
\hline Spectral range & $167-785 \mathrm{~nm}$ \\
Viewing & Axial \\
RF generator & $40 \mathrm{MHz}$ \\
Torch & All-quartz \\
Injector tube diameter & $2.3 \mathrm{~mm}$ \\
Power & $1.25 \mathrm{~kW}$ \\
Plasma flow & $15 \mathrm{~L} \mathrm{~min}^{-1}$ \\
Auxiliary flow & $1.5 \mathrm{~L} \mathrm{~min}^{-1}$ \\
Nebulizer flow & $0.65 \mathrm{~min}^{-1}$ \\
Replicate read time & $3 \mathrm{~s}$ \\
Replicates & 3 \\
Instr. stabilization delay & $20 \mathrm{~s}$ \\
Sample uptake delay & $25 \mathrm{~s}$ \\
Rinse time & $20 \mathrm{~s}$ \\
Sample uptake rate & $0.8 \mathrm{~mL} \mathrm{~min}$ \\
\hline
\end{tabular}

consists of a V-groove nebulizer and a reduced-volume SturmanMasters type spray chamber made of poly(tetrafluorethylene) (PTFE) and is a modified version of a Babington nebulizer. The solution was nebulized when it flowed through the orifice in the V-groove. The inner surface of the spray chamber has a rough surface to ensure proper drainage. A target integration time was set using the instrument software, according to the intensity of the spectral line to obtain the optimum signal-to-background ratio (SBR). The operating parameters and selected analytical lines are listed in Tables 1 and 2, respectively.

\section{Slurry preparation}

Grinding method. Two different sizes of $\mathrm{TiO}_{2}$ particles were selected for testing. The $\mathrm{nm}$ particle size sample (provided by Shanghai University, P. R. China) was utilized directly without grinding. The SRM $154 \mathrm{~b} \mathrm{TiO}_{2}(\mathrm{NBS}, \mathrm{USA}) \mu \mathrm{m}$ particle size sample was screened through a $44 \mu \mathrm{m}$ (325 meshes) sieve. The material was ground in the lab by a 'puck-type grinder' for 2 min, which reduced the particle sizes by the action of a spinning puck and a ring inside a tungsten carbide grinding container. The ground sample was oven-dried at $110{ }^{\circ} \mathrm{C}$ for $2 \mathrm{~h}$.

Dispersion of slurries. Slurries were prepared by weighing the $\mathrm{TiO}_{2}$ sample which was then transferred into a $100 \mathrm{~mL}$ volumetric flask containing $\mathrm{NH}_{4} \mathrm{PAA}$ (Aldrich Chemical Co., USA) $\left(0.5 \mathrm{wt}^{\%} \mathrm{NH}_{4} \mathrm{PAA}\right.$ relative to the ground $\mu \mathrm{m}$ particle size powder and $1.5 \mathrm{wt} \% \mathrm{NH}_{4} \mathrm{PAA}$ for the $\mathrm{nm}$ particle size $\mathrm{TiO}_{2}$ ). The $\mathrm{pH}$ was adjusted to a desired value with aqueous $\mathrm{HCl}$ or $\mathrm{NH}_{3}$. Before nebulization the slurry was agitated in an ultrasonic bath for 15 min to ensure stable dispersion.

Particle size determination. Particle sizes of SRM $154 \mathrm{~b} \mathrm{TiO}_{2}$ were determined by SICAS-4800 photo-sedimentometry (Shanghai Institute of Ceramics, CAS). Both the particle size and the zeta potential for the nm particle size $\mathrm{TiO}_{2}$ were determined by a laser diffraction analyser (Brookhaven Instruments Corporation, USA). The distribution of particles is illustrated in Fig. 1.

Table 2 Selected analytical lines

\begin{tabular}{ll}
\hline Element & Spectral line(s)/nm \\
\hline $\mathrm{Ca}$ & $315.887,317.933$ \\
$\mathrm{Cr}$ & 206.149 \\
$\mathrm{Fe}$ & $234.350,238.204$ \\
$\mathrm{Mg}$ & $280.270,285.213$ \\
$\mathrm{P}$ & $213.618,214.914$ \\
$\mathrm{~Pb}$ & 217.00 \\
$\mathrm{~V}$ & 309.310 \\
$\mathrm{~K}$ & 766.491 \\
$\mathrm{Si}$ & $250.690,252.851$ \\
$\mathrm{Al}$ & 396.152 \\
\hline
\end{tabular}
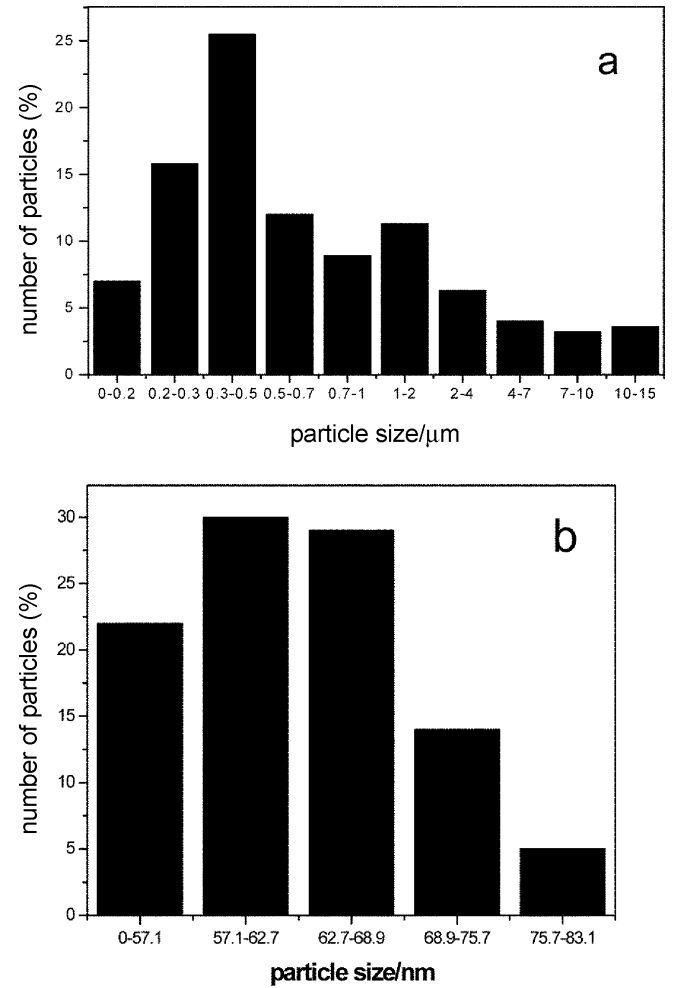

Fig. 1 Bar diagram for particle size distribution of the slurries: (a) $\mathrm{SRM} 154 \mathrm{~b} \mathrm{TiO}_{2}$, determined by photosedimentometry ( $\mathrm{pH} \mathrm{10}$; $0.5 \mathrm{wt} \% \mathrm{NH}_{4} \mathrm{PAA}$ ) and (b) nm particle size $\mathrm{TiO}_{2}$ determined by a laser diffraction analyzer $\left(\mathrm{pH} 10 ; 1.5 \mathrm{wt} \% \mathrm{NH}_{4} \mathrm{PAA}\right)$.

Reagents and samples. All reagents were of guaranteed grade. The solutions were prepared with Milli-Q water (18 M $\Omega$ $\mathrm{cm})$. Calibration curves were established by using aqueous standards. The multielement standards were prepared from $1000 \mathrm{mg} \mathrm{L}^{-1}$ aqueous standards (Shanghai Institute of Measurement and Testing Technology, Shanghai, China). The blank and standards were prepared containing the same amount of dispersant.

Samples were also prepared by alkaline fusion. The sample $(0.1 \mathrm{~g})$ was mixed with an alkaline flux $\left(2 \mathrm{~g}, \mathrm{Na}_{2} \mathrm{CO}_{3}+\right.$ borax $)$ and fused in a Pt crucible for $30 \mathrm{~min}$. After cooling to room temperature, water was added to cover the fusion cake and the sample was left overnight. The dissolved sample solution was transferred into a Teflon beaker, several drops of $\mathrm{H}_{2} \mathrm{O}_{2}$ added, and then allowed to boil. The resulting solution was made up to a volume of $100 \mathrm{~mL}$ with water. Samples were also prepared by acid dissolution. The $\mathrm{TiO}_{2}$ sample was mixed with $2 \mathrm{~mL} \mathrm{H}_{2} \mathrm{SO}_{4}$ and $1 \mathrm{~g}\left(\mathrm{NH}_{4}\right)_{2} \mathrm{SO}_{4}$ in a quartz beaker, and heated till fuming. After the solution was clear, the beaker was cooled to room temperature, and several drops of $\mathrm{H}_{2} \mathrm{O}_{2}$ added. The resulting solution was diluted to $100 \mathrm{~mL}$ with water.

\section{Results and discussion}

Fig. 1(a) shows that the particle size of the ground SRM $154 \mathrm{~b}$ $\mathrm{TiO}_{2}$ powder $(90 \%)$ is less than $5 \mu \mathrm{m}$ while Fig. 1(b) shows that the size of $\mathrm{nm}$ particle size $\mathrm{TiO}_{2}$ is far less than $1 \mu \mathrm{m}$. It is well known that the particle size distribution of a slurry is a limiting factor of controlling analytical recovery. Slurry nebulization requires that both the transport efficiency and the atomization efficiency for the slurry particles must be, as much as possible, identical to those of an aqueous solution. ${ }^{18}$ In our case the criteria described above are fulfilled and calibration can thus be established with aqueous standards. Broekaert et al. ${ }^{19}$ reported that slurry particles should be smaller than $5-10 \mu \mathrm{m}$ during ceramic analysis. The conclusion of the most rigorous studies is that slurry particles larger than $5 \mu \mathrm{m}$ (in some studies $2 \mu \mathrm{m}$ ) do 


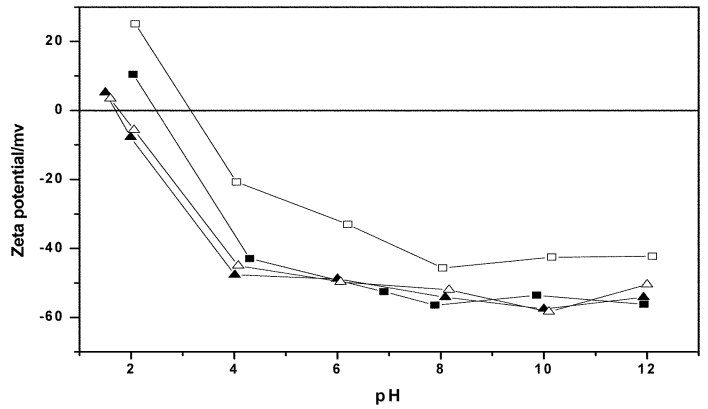

Fig. 2 Profiles of zeta potential vs. $\mathrm{pH}$ for $\mathrm{nm}$ particle size $\mathrm{TiO}_{2}$ slurry at different $\mathrm{NH}_{4}$ PAA concentrations: $(\square) 0 \mathrm{wt} \%$, (口) $0.5 \mathrm{wt} \%$, ( $\square$ ) $1.0 \mathrm{wt}^{\mathrm{O}} \%,(\triangle) 2.0 \mathrm{wt}^{\mathrm{O}} \%$

not reach the plasma and result in a loss of signal. ${ }^{10}$ The transport efficiency and atomization efficiency of the slurries and aqueous standards can thus be considered as the same. The statement has been verified via the analysis of the Standard Reference Material $154 \mathrm{~b} \mathrm{TiO}_{2}$ in this work.

The zeta potential of nm particle size $\mathrm{TiO}_{2}$ slurry $v s . \mathrm{pH}$ at different $\mathrm{NH}_{4}$ PAA concentrations is plotted in Fig. 2. Preparing slurries in aqueous solution alone was unsuitable owing to agglomeration or flocculation effects. Superfine $\mathrm{TiO}_{2}$ powder contains polar particles, which can be stably dispersed in polar medium such as ethanol or water. On the other hand, $\mathrm{TiO}_{2}$ powder surface absorbs air and other pollutants, which affects its dispersion state in liquids. It is therefore essential to use a dispersion agent to prepare stable and homogeneous slurries, yielding accurate and precise analytical results. In this work, $\mathrm{NH}_{4}$ PAA was used as a dispersant.

The stability of the suspended slurry is related to the electrostatic interaction between the particles and the nature of the medium, which can be described in terms of the zeta potential of the system. Fig. 2 shows that the zeta potential varies with $\mathrm{pH}$, and different amounts of the additive $\mathrm{NH}_{4} \mathrm{PAA}$ results in different zeta potentials. The isoelectric points (IEP) are found near $\mathrm{pH} 2.0$, whereas a simple aqueous slurry without additive shows the IEP at $\mathrm{pH}$ 4.5. The experimental results that the zeta potential at $\mathrm{pH} 4$ drops from about $-20 \mathrm{mV}$ for a simple aqueous slurry to about $-45 \mathrm{mV}$ for spiked slurries can be explained by the Ohshima statement. ${ }^{20}$ The zeta potentials were essentially constant in range of $\mathrm{pH}$ 4-10, which gives the appropriate $\mathrm{pH}$ conditions for slurry preparation. Similar stability conditions for a simple aqueous slurry should be $\mathrm{pH} 8-10$ and the prepared slurry is unsuitable for nebulization because of its high viscosity. ${ }^{15}$

Fig. 3 shows the relationships between the mean diameter of the $\mathrm{TiO}_{2}$ particles and the added amount of the dispersant. When no dispersant was added $\left(0.0 \% \mathrm{NH}_{4} \mathrm{PAA}\right)$ a maximum size occurs owing to particle agglomeration. When dispersant is added, the long carbon chain of $\mathrm{NH}_{4} \mathrm{PAA}$ will be adsorbed on to the surface of the particles, its negative electric charge makes

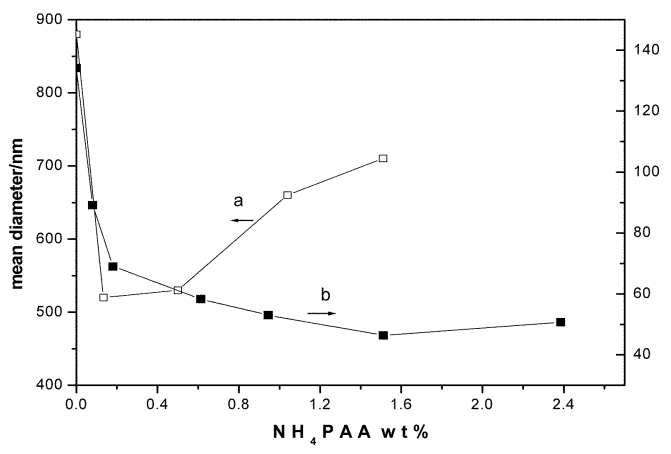

Fig. 3 Curves of mean diameter as a function of $\mathrm{NH}_{4} \mathrm{PAA}$ at $\mathrm{pH}=$

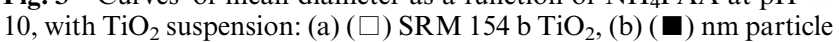
size $\mathrm{TiO}_{2}$.
Table 3 Mean values ( $\mu \mathrm{g} \mathrm{g}^{-1}$ ) and precision ${ }^{a}$ for determination of micro and trace elements in SRM154 $\mathrm{b} \mathrm{TiO}_{2}$

\begin{tabular}{lcrrr}
\hline Element & $\begin{array}{l}\text { Stated } \\
\text { value }\end{array}$ & $\begin{array}{l}\text { Slurry } \\
\text { method }\end{array}$ & $\begin{array}{l}\text { Acid } \\
\text { digestion }\end{array}$ & $\begin{array}{l}\text { Alkaline } \\
\text { fusion }\end{array}$ \\
\hline $\mathrm{SiO}_{2}$ & 100 & $108 \pm 11$ & - & $104 \pm 8$ \\
$\mathrm{CaO}$ & $\sim 100$ & $94 \pm 7$ & $136 \pm 8$ & $101 \pm 11$ \\
$\mathrm{MgO}$ & $\sim 100$ & $156 \pm 14$ & $114 \pm 6$ & $122 \pm 10$ \\
$\mathrm{P}$ & 170 & $153 \pm 14$ & $133 \pm 9$ & $134 \pm 12$ \\
$\mathrm{Fe}$ & 40 & $35 \pm 6$ & $33 \pm 3$ & $34 \pm 4$ \\
$\mathrm{~Pb}$ & 30 & $32 \pm 3$ & $22 \pm 3$ & - \\
$\mathrm{V}$ & $\sim 10$ & $6 \pm 3$ & $10 \pm 1$ & $11 \pm 2$ \\
$\mathrm{Cr}$ & $\sim 5$ & $7 \pm 2$ & $8 \pm 2$ & - \\
${ }^{a}$ Mean value $\pm \mathrm{SD}(n=5)$ & & & \\
\hline
\end{tabular}

Table 4 Mean values $\left(\mu \mathrm{g} \mathrm{g}^{-1}\right.$ ) and precision $^{a}$ for determination of micro and trace elements in $\mathrm{nm}$ particle size $\mathrm{TiO}_{2}$

\begin{tabular}{lrrr}
\hline Element & \multicolumn{1}{c}{$\begin{array}{l}\text { Slurry } \\
\text { method }\end{array}$} & $\begin{array}{l}\text { Acid } \\
\text { digestion }\end{array}$ & \multicolumn{1}{c}{$\begin{array}{l}\text { Alkaline } \\
\text { fusion }\end{array}$} \\
\hline $\mathrm{SiO}_{2}$ & $296 \pm 10$ & - & $317 \pm 8$ \\
$\mathrm{P}$ & $1173 \pm 59$ & $1040 \pm 40$ & $1030 \pm 52$ \\
$\mathrm{Fe}$ & $110 \pm 10$ & $94 \pm 5$ & $93 \pm 4$ \\
$\mathrm{Al}$ & $102 \pm 5$ & $98 \pm 2$ & $104 \pm 4$ \\
$\mathrm{~K}$ & $2388 \pm 62$ & $2430 \pm 30$ & $2250 \pm 42$ \\
$\mathrm{Mg}$ & $24 \pm 1$ & $46 \pm 5$ & - \\
$\mathrm{Pb}$ & $41 \pm 5$ & $32 \pm 2$ & - \\
${ }^{a}$ Mean value $\pm \mathrm{SD}(n=5)$. & & \\
\hline
\end{tabular}

the particles repel each other and the slurry is well dispersed and stable. The nm particle size $\mathrm{TiO}_{2}$ has a large specific surface area and requires more $\mathrm{NH}_{4} \mathrm{PAA}$ to disperse the particles. Besides, use of $\mathrm{NH}_{4}$ PAA makes possible to determine $\mathrm{Na}$ and $\mathrm{P}$ in $\mathrm{TiO}_{2}$, compared with the use of sodium hexametaphosphate as dispersant.

The analytical results of micro and trace elements determined in SRM $154 \mathrm{~b} \mathrm{TiO}$ and nm particle size $\mathrm{TiO}_{2}$ are shown in Tables 3 and 4, respectively. Micro and trace elements $(\mathrm{P}, \mathrm{Si}$, $\mathrm{Fe}, \mathrm{Pb}, \mathrm{Ca}, \mathrm{V}, \mathrm{Cr}$ and $\mathrm{Mg}$ ) in $\mathrm{SRM} 154 \mathrm{~b} \mathrm{TiO}_{2}$ and $(\mathrm{Fe}, \mathrm{P}, \mathrm{Pb}$, $\mathrm{Si}, \mathrm{Al}, \mathrm{Mg}$ ) in $\mathrm{nm}$ size $\mathrm{TiO}_{2}$ were determined by using a slurry method and compared with the results obtained by the acid digestion and alkaline fusion methods. Satisfactory recovery can be obtained by fusion of the samples, as $\mathrm{TiO}_{2}$ is a chemically resistant refractory material; $\mathrm{Si}$ can be determined with good accuracy. The prepared solutions are stable for extended times. A disadvantage of the alkaline fusion is that the concentrations of some trace elements are too low to be determined due to the dilution. Acid decomposition could not digest $\mathrm{TiO}_{2}$ samples completely, and $\mathrm{SiO}_{2}$ cannot be determined if a quartz container was used. Slurry sampling in the plasma can overcome all the above problems and the impurities in $\mathrm{TiO}_{2}$ can be determined directly.

The determined results by the slurry introduction method were in good accordance with the stated values, which verified that calibration curves could be established by aqueous standards. This also indicated that axially viewed ICP can be used for the analysis of $\mathrm{TiO}_{2}$ slurries or some other resistant refractory materials.

\section{Conclusions}

$\mathrm{TiO}_{2}$ can be prepared as stable slurries for sample introduction in ICP-OES analysis with calibration by aqueous standards. The slurries are stabilized if appropriate amounts of $\mathrm{NH}_{4} \mathrm{PAA}$ are added.

\section{Acknowledgements}

The authors are grateful to Shanghai Committee of Science and Technology $(0159 \mathrm{~nm} 075)$ for financial support. 


\section{References}

1 E. M. Logothetis, Ceram. Eng. Sci. Prog., 1980, 1, 281.

2 J. A. C. Broekaert, T. Graule, H. Jenett, G. Tolg and P. Tschopel, Fresenius' J. Anal. Chem., 1989, 332, 825.

3 T. Peng, P. Du, B. Hu and Z. Jiang, Anal. Chim. Acta, 2000, 421, 75.

4 J. Schwitzgebel, J. G. Ekerdt, H. Gerischer and A. Heller, J. Phys. Chem., 1995, 99, 5633.

5 J. M. G. Amores, V. S. Escribano and G. Busca, J. Mater. Chem., $1995, \mathbf{5}, 1245$.

6 T. Chen and F. Shan, J. Anal. Lab., 1998, 2, 47 (in Chinese).

7 L. Ebdon, M. Foulkes and K. Sutton, J. Anal. At. Spectrom., 1997, 12, 221.

8 C. S. Silva, T. Blanco and J. A. Nobrega, Spectrochim. Acta, Part B, 2002, 57, 30 .

9 B. Brenner, A. Zander, M. Cole and A. Wiseman, J. Anal. At. Spectrom., 1997, 12, 897.

10 B. Brenner, M. Zischka, B. Maichin and G. Knapp, J. Anal. At. Spectrom., 1998, 13, 1257.
11 B. Brenner and A. Zander, Spectrochim. Acta, Part B, 2000, 55 1195 .

12 I. Marjanovic, R. I. McCrindle, B. M. Botha and J. H. Potgieter, J. Anal. At. Spectrom., 2000, 15, 983.

13 J. A. C. Broekaert, F. Leis, B. Raeymaekers and G. Y. Zaray, Spectrochim. Acta, Part B, 1988, 4(5), 349.

14 T. Peng, Q. Yan and B. Hu, Chem. J. Chinese Univ., 2000, 5, 694 (in Chinese).

15 J. C. Farinas, R. Moreo and J. M. Mermet, J. Anal. At. Spectrom., 1994, 9, 841 .

16 J. Wang, L. Gao, J. Sun and Q. Li, J. Colloid Interface Sci., 1999, 213, 552 .

17 T. Zander, B. Cooper and C. Ring-Ling, US Pat., 5596407, Jan. 21, 1997.

18 P. Goodall, M. E. Foulkes and L. Ebdon, Spectrochim. Acta, Part $B, 1993,48,1563$.

19 J. A. C. Broekaert, C. Lathen and R. Brandt, Fresenius' J. Anal. Chem., 1994, 349, 20.

20 H. Ohshima, J. Colloid Interface Sci., 1997, 185, 269. 